\title{
High Beta Flux-Conserving Tokamaks
}

\author{
J. F. Clarke
}

\section{MASTER}

\section{OAK RIDGE NATIONAL LABORATORY}




\section{DISCLAIMER}

This report was prepared as an account of work sponsored by an agency of the United States Government. Neither the United States Government nor any agency Thereof, nor any of their employees, makes any warranty, express or implied, or assumes any legal liability or responsibility for the accuracy, completeness, or usefulness of any information, apparatus, product, or process disclosed, or represents that its use would not infringe privately owned rights. Reference herein to any specific commercial product, process, or service by trade name, trademark, manufacturer, or otherwise does not necessarily constitute or imply its endorsement, recommendation, or favoring by the United States Government or any agency thereof. The views and opinions of authors expressed herein do not necessarily state or reflect those of the United States Government or any agency thereof. 


\section{DISCLAIMER}

Portions of this document may be illegible in electronic image products. Images are produced from the best available original document. 
Printed in the United States of America: Available from Natinnal Terhnical Information Service

U.S. Department of Commerce

5285 Port Royal Road, Springfield, Virginia 22161

Price: Printed Copy $\$ 4.00$; Microfiche $\$ 2.25$

This report was prepared as an account of work sponsored by the United States Government. Neither the United States nor the Energy Research and Development Administration/United States Nuclear Regulatory Commission, nor any of their employees, nor any of their contractors, subcontractors, or their employees, makes any warranty, express or implied, or assumes any legal liability or responsibility for the accuracy, completeness or usefulness of any information, apparatus, product or process disclosed, or represents that its use would not infringe privately owned rights. 
Contract No. W-7405-eng-26

THERMONUCLEAR DIVISION

HIGH BETA FLUX-CONSERVING TOKAMAKS

J. F. Clarke

\section{JUNE 1976}

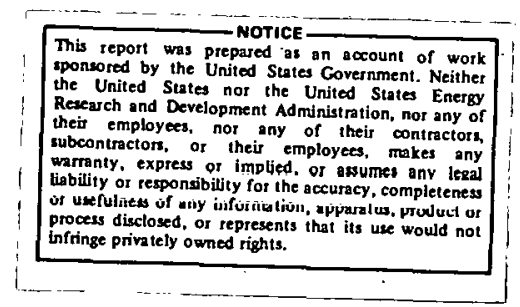

OAK RIDGE NATIONAL LABORATORY

Oak Ridge, Tennessee 37830

operated by

UNION CARBIDE CORPORATION

for the

ENERGY RESEARCH \& DEVELOPMENT ADMINISTRATION 


\section{THIS PAGE \\ WAS INTENTIONALLY \\ LEFT BLANK}


CONTENTS

Page

ACKINOWLEDGMENTS

V

INTRODUCTION

1

HIGH BETA EQUILIBRIA

1

CONCLUSION

27

REFERENCES

29

DISTRIBUTION LIST 


\section{THIS PAGE}

\section{WAS INTENTIONALLY \\ LEFT BLANK}




\section{ACKNOWLEDGMENT}

The concepts in this report were developed in extended interactions with Lee Berry, Jim Callen, Bob Dory, Martin Peng, and Fred Marcus, all of ORNL, and with Dieter Sigmar of MIT. Calculations resulting in the figures were performed by Martin Peng and Bob Dory. Individual publications reflecting the work which I have summarized will be appearing shortly. 


\section{HIGH BETA FLUX-CONSERVING TOKAMAKS}

J. F. Clarke

\section{INTRODUCTION}

In any magnetically confined fusion device, there is a premium on operation at the highest possible beta because the fusion power output at a fixed magnetic.field depends on the square of the beta. Since much of the capital cost of a magnetically confined fusion reactor is associated with the production of magnetic fields, high beta operation is a necessary ingredient in the formulation of a low capital cost syștem.' With regard to tokamaks, there is a widely held conception that the attainable beta is limited by equilibrium constraints. This has led to the design of a number of low beta tokamak reactor systems, and has thereby imposed severe constraints on the economic viability of these systems. ${ }^{1-4}$. It is the purpose of this memo to show that this widely used beta limit on tokamaks is highly dependent on the method of achieving the high beta equilibrium and that a class of systems exists which is not subject to any equilibrium beta limit at all. In these systems the ultimate limitation on beta must be found from magneto-hydrodynamics (MHD) stability theory, not from equilibrium considerations.

\section{HIGH BETA EQUILIDRIA}

The origin of the belief in an equilibrium beta limit in tokamaks is connected with the early work of Shafranov. 5 In his considerations, Shafranov arrived at limiting values of poloidal beta determined by the condition that a separatrix in the magnetic structure coincided with the surface of the plasma. This can be visualized by referring to Fig. 1, which shows that the basic equilibrium field of a tokamak is made up by the superposition of a poloidal field on a vertical field. Since the poloidal field and the vertical field are in opposite directions on the interior of the torus, Shafranov showed that for two particular current distributions, a skin current and a uniform current distribution throughout the plasma, a solution exists in which a separatrix concides with the 
ORNL - DWG $76-4268$

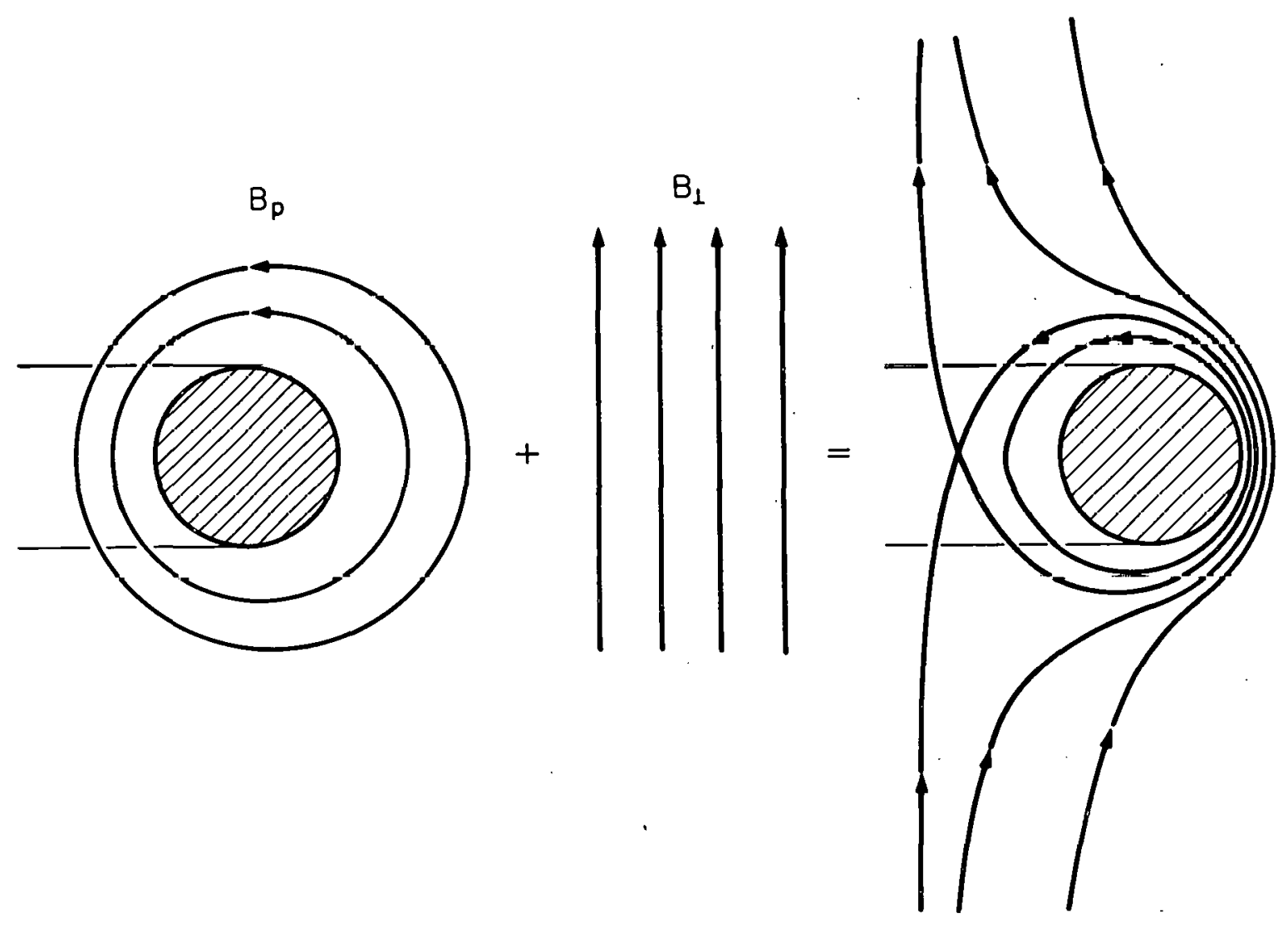

Fig. 1. Figure 1 shows the superposition of fields providing major radius equilibrium in a low beta tokamak. 
innermost surface of the plasma torus. Referring to Fig. 1, if one imagines that the plasma pressure is increased in the shaded area and that the poloidal field surrounding the plasma is not increased, the system will expand in major radius. Major radius equilibrium must be maintained by an increase in the vertical field. This will inevitably lead to the separatrix, shown on the right of Fig. 1, approaching and finally intersecting the surface of the plasma. An analysis of this sequence of events yields the result that the maximum poloidal beta, $\beta_{j}^{c}$, corresponds roughly to the aspect ratio of the plasma.

However, in beginning his analysis, Shafranov notes that "the critical value $\beta_{1}^{c}$ depends on current distribution in the configuration." Except in certain ideal cases, the argument based on a consideration of the magnetic field in Fig. $I$ is flawed by the fact that it does not take proper account of the changes in poloidal field which will follow upon the increase of beta. If the plasma currents flowing within the shaded area of Fig. 1 are themselves responsible for providing some of the vertical field $B_{\perp}$ necessary for equilibrium, it is conceivable that the increased vertical field could be added in an asymmetric manner (See Fig. 2). In this case the increase of plasma. pressure could be accommodated without moving the separatrix appreciably closer to the surface of the plasma. Noting this at the conclusion of his analysis, Shafranov remarks :

"It should be borne in mind that the presence of a critical $\beta_{1}^{c}$, generally speaking, does not mean that the value of permissible plasma pressure in the tokamak has a limit. In fact, let a plasma column he generated inside an ideal casing. If the plasma is rapidly heated sufficiently so that the condition of 'freezing' of the magnetic field in the plasma is satisfied, then the topology of the magnetic configuration cannot be disturbed, i.e., even on unlimited increase of pressure, the topology of the enclosed toroidal magnetic surfaces with one magnetic axis theoretically remains unchanged."

As an example of this latter condition, Shafranov refers to the work of Callen and Dory. 6

In this work, Callen and Dory analyzed the conditions for attaining high beta equilibria in axisymmetric tokamak configurations. They also show that the flux function describing the magnetic surfaces containing 
the plasma can be obtained from:

$$
\Delta * \Psi=-4 \pi\left(R^{2} p^{\prime}+F F^{\prime}\right),
$$

where $\Psi$ is the plasma flux function, $R$ is the major radius, $p$ ' is the derivative of the plasma pressure with respect to magnetic flux, and $F$ is equal to $\mathrm{RB}_{\Phi}$. They demonstrated that equilibria exist for poloidal beta in excess of the aspect ratio without a separatrix intersecting the surface of the plasma.

However, these high beta equilibria were obtained by exploiting the fact that the function $F$ is arbitrary in equilibrium theory. Adjusting $F$ in a manner ${ }^{7}$. which kept the total current constant led to the examples of high beta equilibria shown in Fig. 3. Since these calculations were done for a system in which the aspect ratio $A$ is equal to three, it is clear that there is no limitation of $\beta_{p}<A$ as $t^{\prime a r}$ as the equilibrium is conccrned. However, Callen and Dory noted that although the function $F$ is arbitrary in equilibrium theory, it is related to other characteristics of the system such as the value of the "safety factor" $q$. Thus the equilibria shown in Fig. 2 do not represent states of a single system.

Callen and Dory found that although they could attain high beta equilibria by manipulation of the function $F$ to maintain constant current, they were simultaneously manipulating the q profile of the equilibrium. They also found that as they increased poloidal beta by varying the function F from low beta to high beta, the $q$ on axis dropped below 1 . It was felt that this would provide a stability limitation on the attainable poloidal beta unless the plasma current was dropped as poloidal beta was increased.

The above analysis and computation illustrate the fact that the specification of a limiting $\beta$ or $\beta_{p}$ in a tokamak is a process involving several variables. The calculations of Callen and Dory also indicate that there is no simple relationship between total $\beta$ and $\beta_{p}$ in high beta equilibria. This follows from the fact that Eq. (2) does not apply to high beta equilibria.

$$
\psi(\text { Luw } B \in L u) \equiv \frac{r}{R} \frac{B_{T}}{B_{p}} .
$$



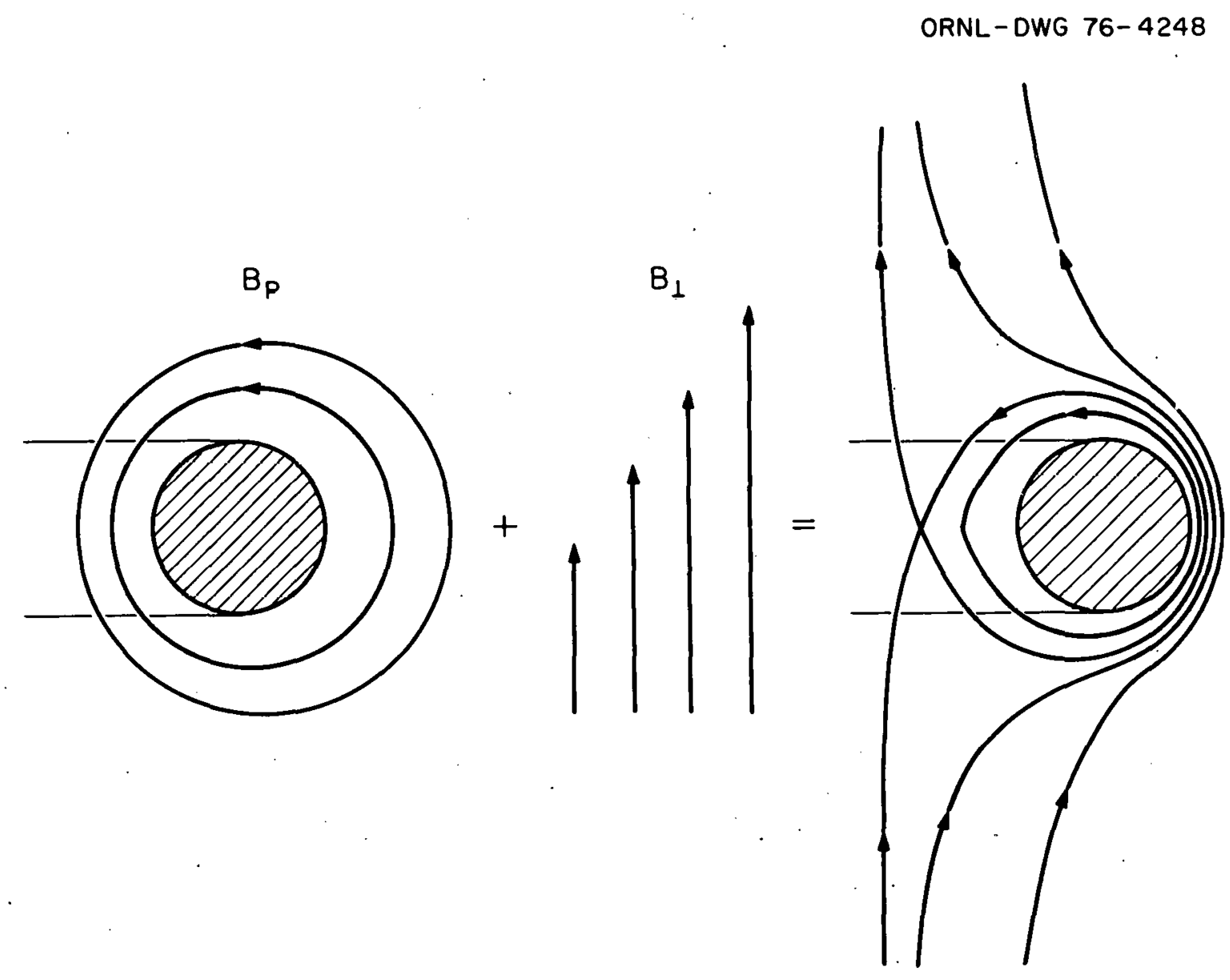

Fig. 2. Figure 2 shows the superposition of fields necessary for major radius equilibrium in a high beta tokamak. The verticle magnetic field within the plasma is produced by plasma currents. In a flux conserving tokamak its distribution is such that no separatrix appears within the plasma as the beta is increased from low to high values. 

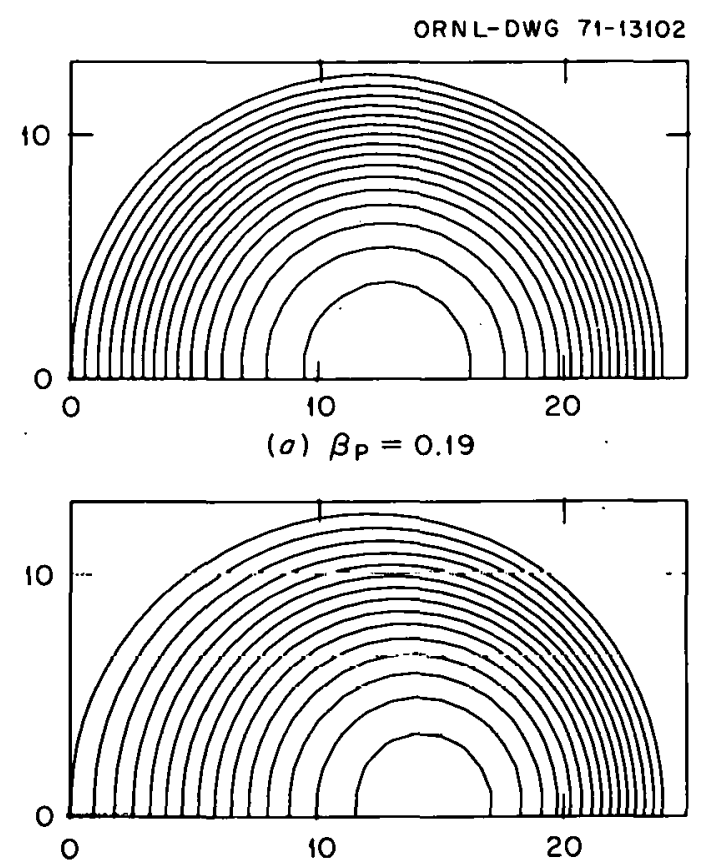

(b) $\beta_{\mathrm{P}}=0.93$

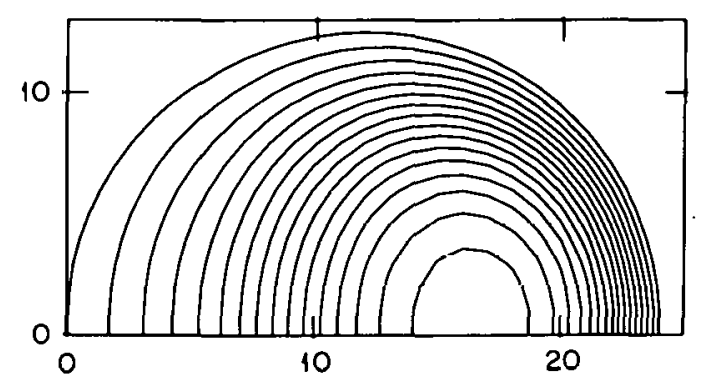

(c) $\beta_{\Gamma}=3.8$

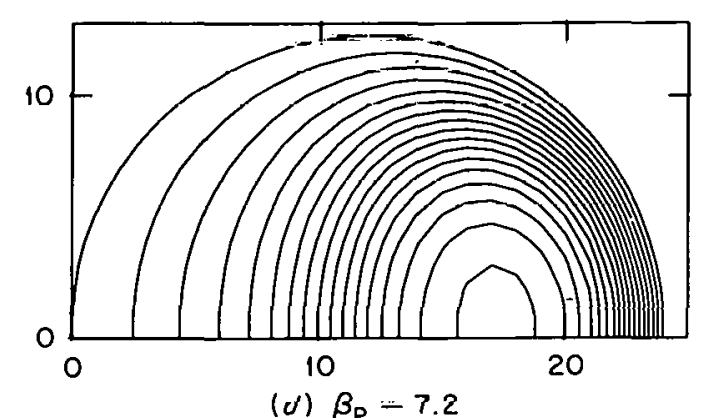

Fig. 3. Figure 3 shows the evolution of plasma magnetic flux surfaces as the poloidal beta is raised in a non-flux conserving manner. Since highly conducting plasmas conserve flux, the sequence of equilibria shown in Figure 3 does not represent states of a single physical system. However, since the calculations were performed for a torus with an aspect ratio of three, it is clear that the poloidal beta is not limited by the aspect ratio. 
It is important to recognize that the safety factor $q$ is a quantity constant on an entire magnetic surface. It is only in the limit of low beta which corresponds to essentially concentric magnetic surfaces that one can interpret $\mathrm{q}$ in terms of a local magnetic field line pitch as in Eq. (2). In the general case of arbitrary beta, $q$ is defined as the ratio of toroidal flux to poloidal flux between two infinitesimally close flux surfaces:

$$
q(\Psi) \equiv \frac{d \Phi}{d \Psi} .
$$

It is easy to show the relationship between $q$ and $F$, since Eq. (3) can be written as

$$
q(\Psi)=\frac{F V^{*}\left\langle R^{-2}\right\rangle}{4 \pi^{2}}
$$

where $V^{\prime}$ is the specific volume between two flux surfaces and $R^{-2}$ is averaged over a flux surface.

Figure 4 shows the difference between high and low beta equilibria with regard to the actual fields found within the plasma. In low beta the plasma pressure and a slight toroidal paramagnetism create an outward pressure which must be balanced by the poloidal field generated by the plasma current. In this circumstance the flux surfaces are nearly concentric, and Eq. (2) applies. One can then write the identity

$$
\beta=\beta_{p} / q^{2} A^{2} .
$$

As the beta is increased, however, the toroidal paramagnetism is reversed and the plasma becomes diamagnetic in the toroidal field. Thus the plasma pressure can now be balanced against both the toroidal field and the poloidal field created by the plasma current. In fact, in this circumstance there is a reversed plasma current on the interior part of the plasma torus and an increase in the plasma current in the outer 


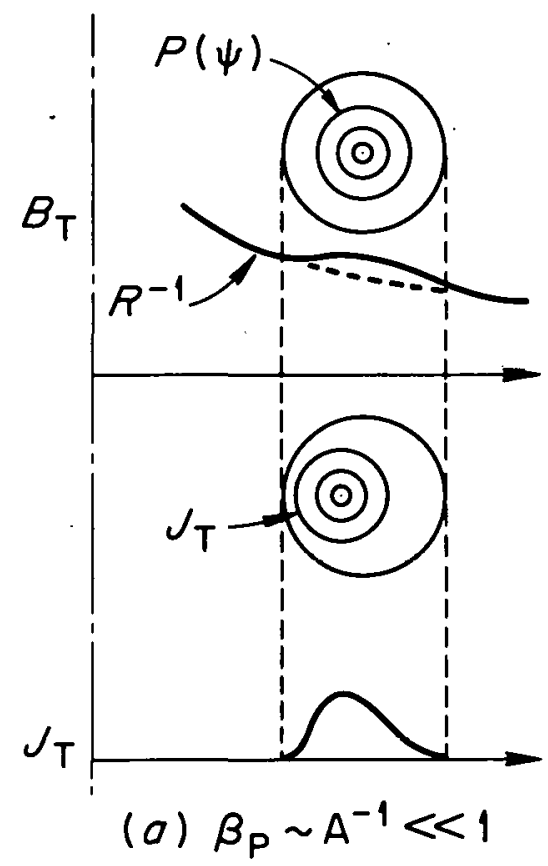

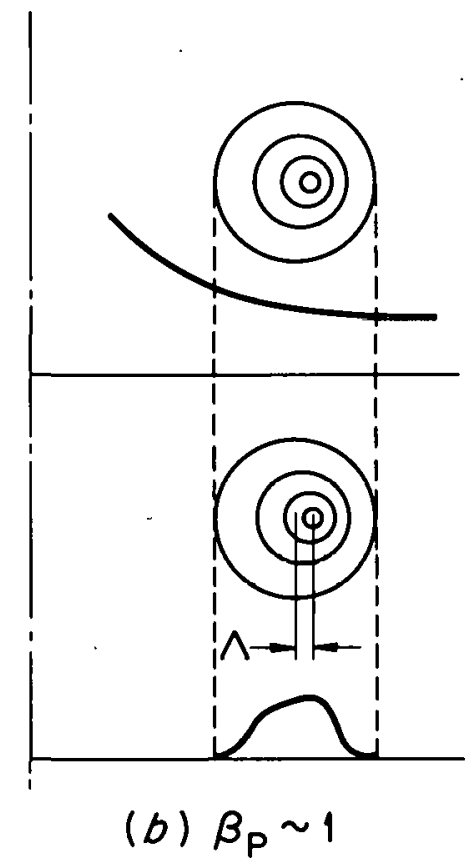

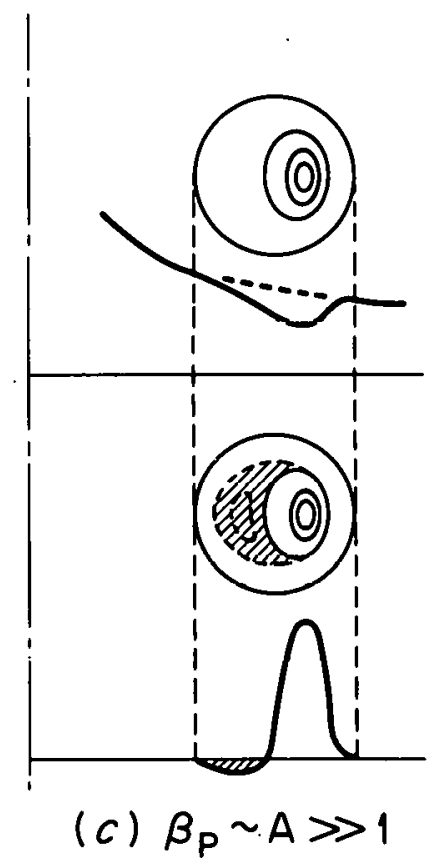

Fig. 4. Figure 4 is a schematic representation of the characteristics of tokamak equilibria. Figure $4 a$ indicates that at low beta the plasma pressure and the pressure due to an increase of the toroidal field over its vacuum value are supported by the poloidal magnetic pressure generated by the current $J_{f}$. Figures $4 b$ and $c$ show that as the plasma pressure is raised currents flow in the plasma such that the toroidal field is reduced below its vacuum value and much of the plasma pressure is supported by this toroidal magnetic field well. Depending on the precise pressure distribution in the plasma, high beta equilibria can require a negative toroidal current to flow on the interior of the torus. These characteristics apply to all high beta equilibria. 
region of the torus. The ratio of beta to poloidal beta in this circumstance is given by:

$$
\beta \equiv \beta_{p} \frac{\left\langle B_{p}^{2}\right\rangle}{B_{T}^{2}}
$$

Because of the highly distorted equilibrium sketched in Fig. 3(c), the ration of magnetic fields in Eq. (6) is not simply given by $1 / \mathrm{q}^{2} \mathrm{~A}^{2}$. Equation (5) implies that given a toroidal and poloidal magnetic field, an increase in pressure would increase the total beta and poloidal beta equally. However, in the highly distorted high beta equilibria shown in Fig. 3, an incremental pressure increase can be shown to increase beta more than it increases poloidal beta. This reflects the fact that the surface average value of the poloidal magnetic energy density is affected as much by the large shifts and distortions experienced by high beta equilibria as by the current originally driven in the plasma. In other words, the plasma can create its own equilibrium poloidal field by shifts of the magnetic axis which cause the poloidal magnetic field to increase in the outer regions of the torus. Since the q also depends on these shifts, as shown by Eq. (4), it is clear that the plasma will simultaneously adjust its safety factor as the pressure is increased.

In an actual experiment, pressure will be added to the system in a prescribed and controllable manner; for example, through the use of neutral injection. The neutral injection process begins by using an ohmically heated plasma as a target. Many experiments have shown that these ohmically heated plasmas are inherently low beta. Consequently, the initial condition from which experimental tokamaks will start the process of heating to high values of beta is similar to that shown in Fig. 4(a). The heating process will then cause the plasma to pass through the equilibrium configurations sketched in Figs. 4(b) and 4(c). A rule is needed for calculating the precise trajectory of the plasma equilibrium as the plasma is heated, so that we may arrive at a realistic estimate of the equilibrium properties of experimentally produced high beta tokamaks. Such a rule is provided by the concept of flux conservation. 
THE FLUX-CONSERVING EQUILIBRIUM

In single fluid MHD theory, Ohm's law is written as

$$
\overrightarrow{\mathrm{E}}+(\overrightarrow{\mathrm{V}} \times \overrightarrow{\mathrm{B}})=\eta \overrightarrow{\mathrm{J}}
$$

If the temperature of the plasma is sufficiently high, the resistivity term on the right-hand side of Eq. (7) can be omitted; the left-hand side then describes the response of the plasma to applied electric fields. It is easily shown from Maxwell's equations that Eq. (7) guarantees that flux is conserved within a plasma.

Eimply otatcd, flux conocrvation moano that tho magnetio 1 "Lux Linking a plasma pressure surface will be preserved in spite of changes in the shape or configuration of that surface. Therefore, the concept of flux conservation can provide a rule which allows us to select the precise sequence of equilibria through which a plasma will pass during the process of being heated to high beta. From the basic definition of q given in Ey. (3), it is clear that these flux-conserving equilibria will also be q-conserving equilibria. This is a fundamental characteristic which distinguishes this sequence of equilibria from those computed by Callen aind Dựy.

Before investigating the characteristics of these flux-conserving equilibrium, it must be remarked that flux conservation is not a concept which is being imposed upon the plasma from the outside. As long as the plasma resistivity is small enough to omit in Eq. (7), the plasma will move in response to external forces in such a way as to preserve flux. A simple analysis of Maxwell's equations will indicate that the time scale on which one can neglect plasma resistivity with regard to flux conservation is

$$
\tau_{S}=49 \mathrm{~T}^{\frac{3}{2}}(a / 100)^{2} \mathrm{sec},
$$


where temperatures are given in keV and dimensions in centimeters. For hot present day experiments, this time is on the order of seconds. However, we are not interested in the time necessary to totally change the flux within a plasma. A more relevant time is one in which the flux configuration changes sufficiently to modify the equilibrium distribution of magnetic fields within the plasma. This so-called configuration time has been defined as :

$$
\tau_{e}=4.9 T_{e}^{\frac{3}{2}}(a / 100)^{2} \mathrm{sec}
$$

In current experiments, this time is on the order of $100 \mathrm{msec}$. However, it should be noted that existing low beta ohmically heated tokamaks arrive at their equilibrium temperature by traversing a number of turbulent resistive stages; consequently, flux conservation does not play a large part in the specification of these initial equilibria. For future devices, Eqs. (8) and (9) predict skin times and magnetic configuration times on the order of hundreds of seconds. Since these advanced machines will arrive at their high temperature, high beta configuration as a result of controlled heating on a time scale of only a few seconds, starting with an already hot ohmically heated plasma, it is hard to imagine a mechanism by which flux conservation could be violated.

In order to calculate flux-conserving equilibria, Eq. (4) is used to specify the function $F$. One chooses a $q$ profile consistent with the low beta equilibria from which the heating process starts and determines the pressure profile $p^{\prime}$ from an analysis of the detailed heating process. With these functions defined, Eq. (1) can be solved to determine the magnetic configuration of the plasma. In practice this turns out to be quite difficult. Thus far we have been able to compute sequences of equilibria which very nearly preserve flux. 8 Figure 5 shows a sequence of pressure profiles labeled by a parameter $\beta_{j}^{\prime}$; the magnetic equilibria corresponding to these pressure profiles very nearly conserve flux, as indicated by the close comparison of the q profiles for a low and a high pressure case (Fig. 6). Figures 7 through 10 show the flux surfaces corresponding to pressure profiles of $B_{j}^{\prime}$ equal to $0,10,40$, and 100 respectively. This sequence of plots indicates that as the pressure is 

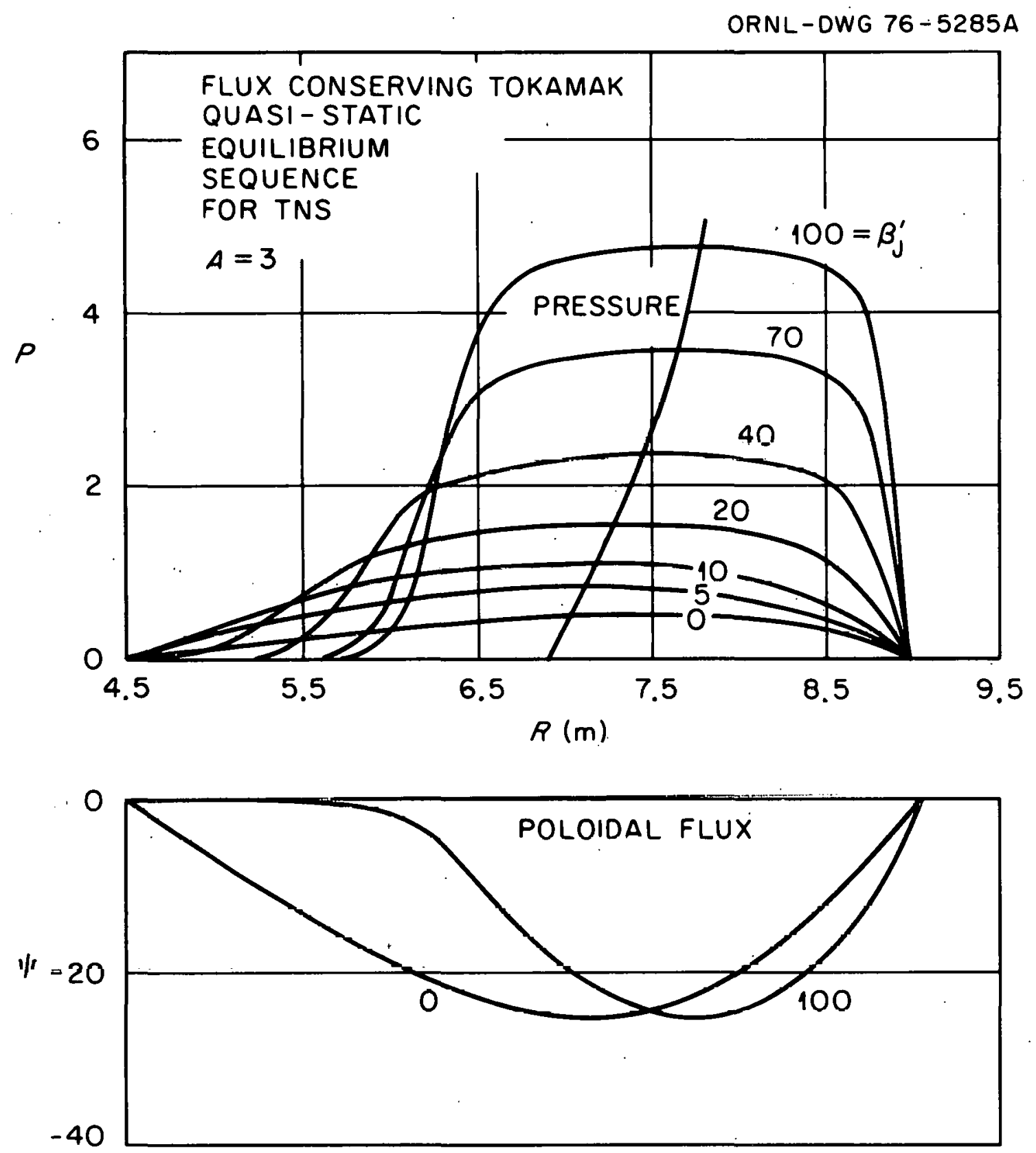

Fig, 5. Figure 5 shows the evolution of the pressure profile, and the flux distribution as the plasma pressure is raised in a flux conserving tokamak. The parameter $\beta_{j}^{\prime}$ is an index labeling the pressure increase in the numerical calculations. In this particular calculations $\beta_{j}^{\prime}=100$ corresponds to a total $\beta$ of roughly $12 \%$. Flux conservation follows from the fact that the central and edge fluxes are kept constant during the pressure increase. 

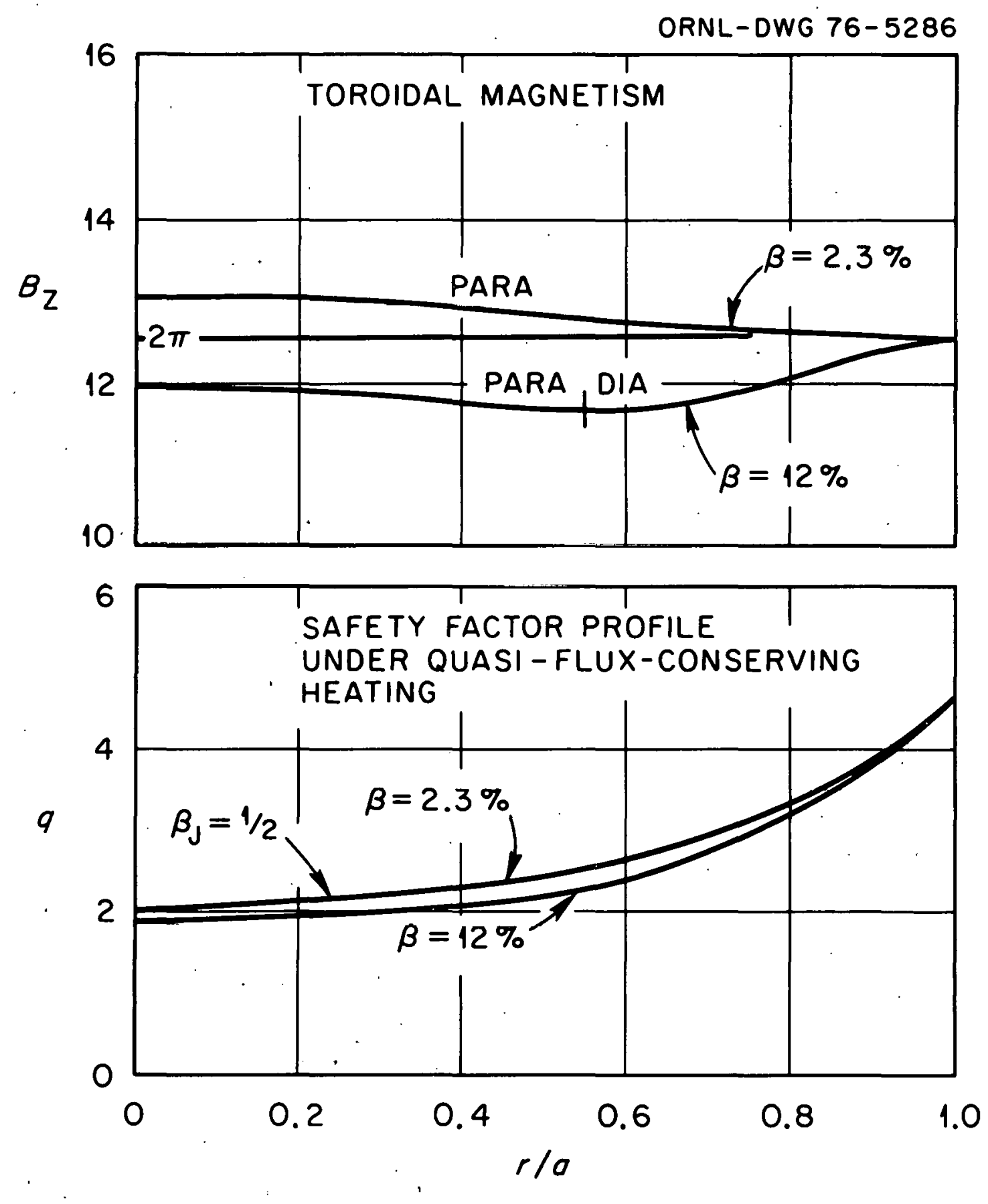

Fig. 6. Figure 6 shows the toroidal field distribution and $q$ profile in the plasma as the beta is raised in a flux conserving manner from $2.3 \%$ to $12 \%$. The small variation of the $q$ profile indicates that the numerical computations are not totally successful in conserving the plasma flux. A truly flux conserving tokamak would preserve the $q$ profile unchanged during the beta increase. 
raised in a quasi-flux-conserving manner, the plasma responds by progressively shifting its magnetic axis toward the outside of the torus, and by progressively assuming less circular shapes.

Figure 5 shows the distribution of poloidal flux and toroidal current corresponding to the initial and final states of the plasma. The close correspondence between the minimum values of the poloidal flux in the low and high beta calculations is another indication that these equilibria are very closely flux-conserving. The toroidal current distribution in these flux-conserving equilibria peaks toward the outside of the torus as in Fig. 4(c). However, there is no reversal of the current in the low pressure interior region. The total current increases, driven by the pressure increase induced by the heating process in the plasma. Stated another way, inductively driven currents are necessary to preserve flux as the plasma pressure is increased.

The toroidal field within the plasma is shown in Fig. 6; the general paramagnetism of the low beta plasma gives way to a diamagnetic effect at higher betas. As in the $\mathrm{EBT}^{9}$, the heating process has caused the plasma to "dig a hole" in the toroidal field, and most of the plasma pressure is supported by this toroidal field well.

An examination of the flux surfaces shown in Figs. 7 through 10 leads one to believe that the general trends revealed by the numerical analysis should be recoverable from an analytic model which treats circular flux surfaces. The deviation from circular f'lux surfaces does not become extreme until the plasma pressure has been raised by more than a factor of 4 or 5. Thus, it will be instructive to examine the evolution of equilibria in an approximate model which conserves flux exactly. We will choose a constant $q$ model in which the magnetic flux surfaces are assumed to be a set of nested circles whose centers, $R_{\Psi}$, are shifted in a manner determined by the distribution of pressure within these surfaces. The simplest model for such a set of flux surfaces is:

$$
\Psi=\Psi_{0} \rho^{2} / a^{2}
$$




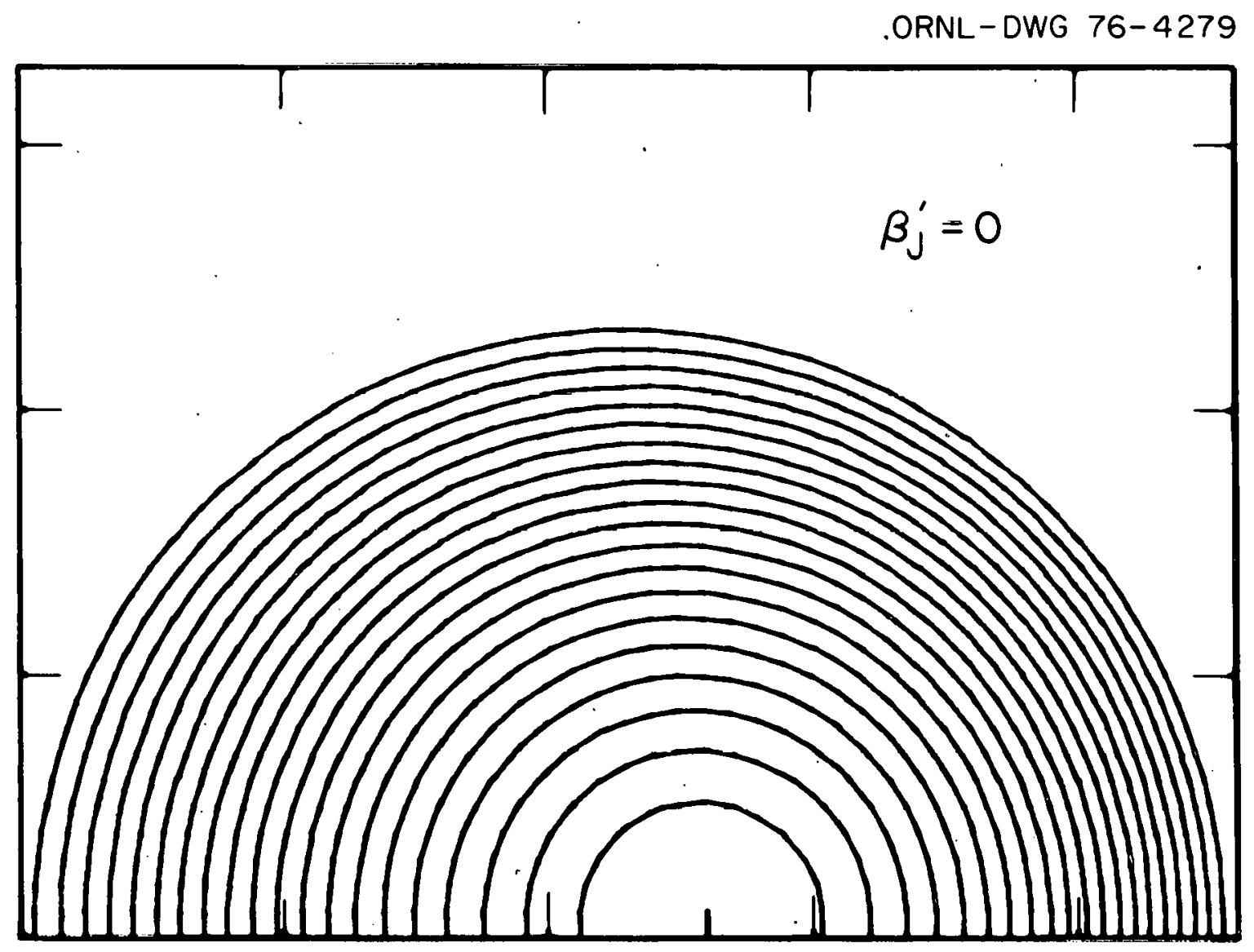

Fig. 7. Figure 7 shows magnetic flux surfaces compatible with the pressure profile indicated by the parameter $\beta_{j}^{\prime}=0$ of Figure 5 . 


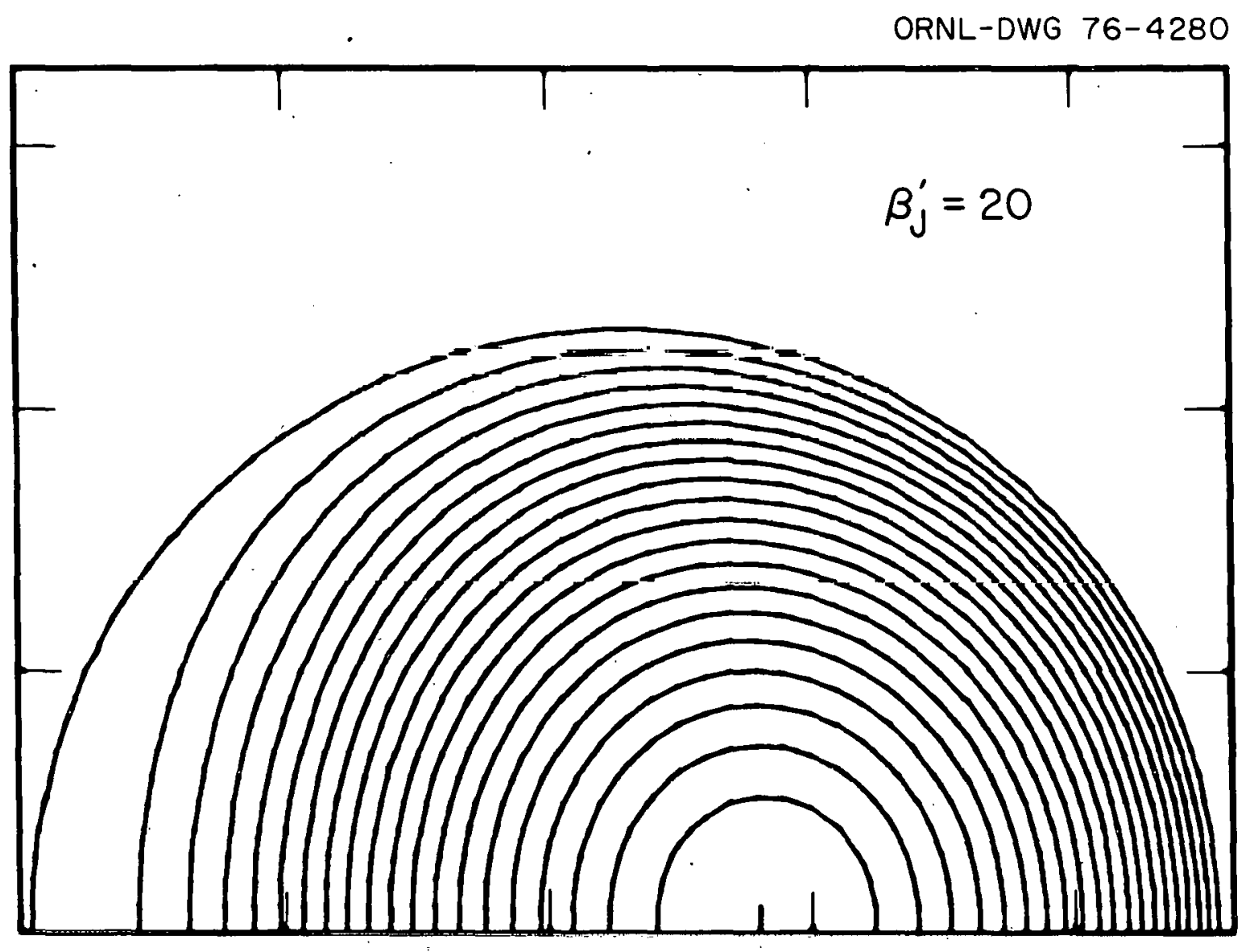

Fig. 8. Figure 8 shows the magnetic flux surfaces compatible with the pressure profile indicated by $\beta_{j}^{-}=10$ in Figure 5 . The flux is the
same as in Figure 7 . 
ORNL-DWG 76-4281

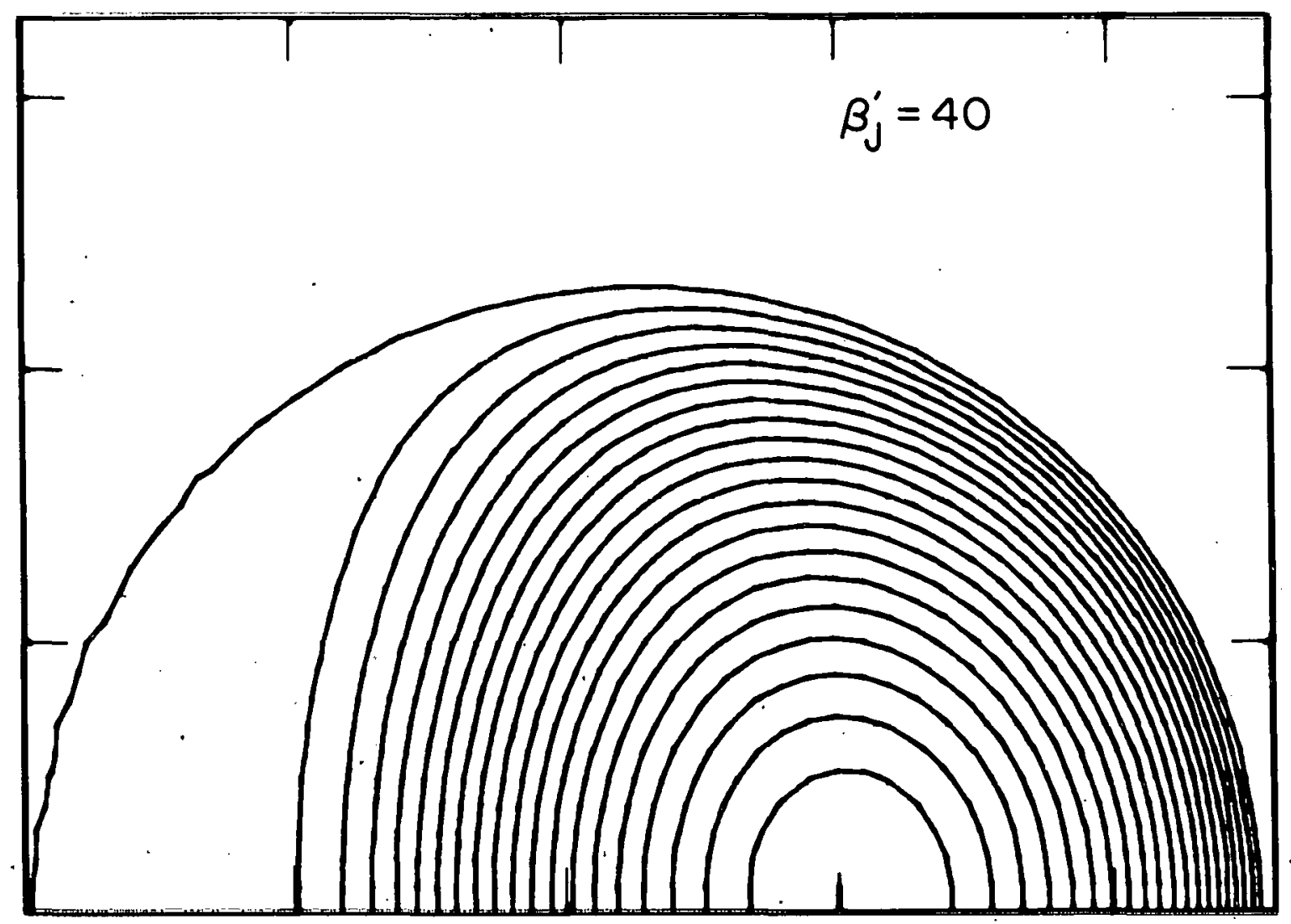

Fig. 9. Figure 9 shows the magnetic flux surfaces compatible with the pressure profile $\beta_{j}^{\prime}=40$ in Figure 5 . The flux is the same as
figures 7 and 8 . 
ORNL-DWG $76-4282$

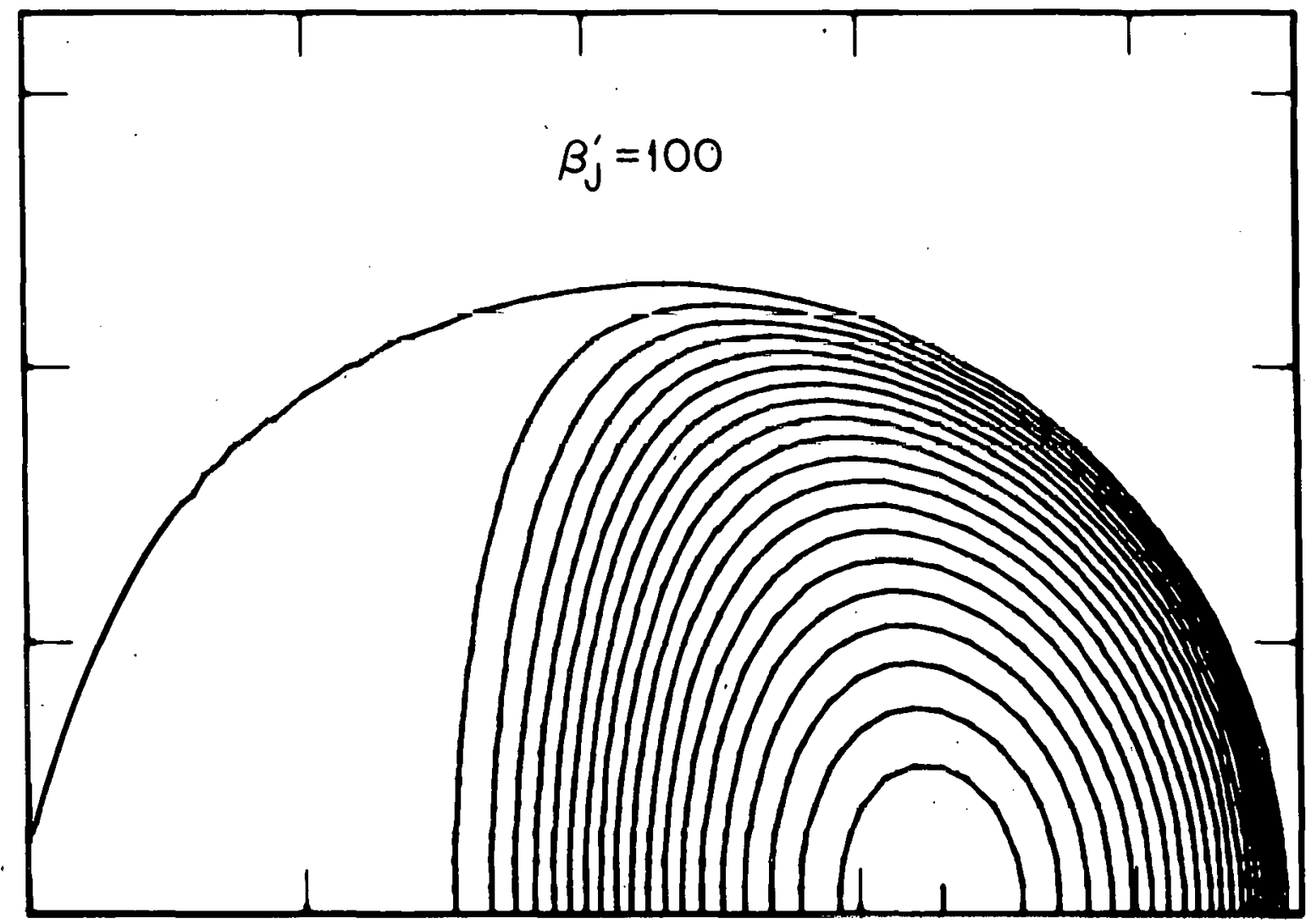

Fig. 10. Figure 10 shows the magnetic flux surfaces consistent with the pressure profile labeled by $\beta_{j}^{\prime}=100$ in Figure 5 . These flux surfaces have evolved in a flux conserving manner from the low beta flux surfaces shown in Figures 7 through 9 and represent an average plasma beta of $12 \%$. 
where $\rho^{2}$ is defined by

$$
\rho^{2}=\left(R-R_{\Psi}\right)^{2}+z^{2}
$$

With this definition of flux, the poloidal magnetic field and its surface average are

$$
\begin{gathered}
B_{p}=\frac{2 \Psi_{0} \rho}{a^{2} R}\left\{\frac{1}{1+\frac{2 \Psi_{0}}{a^{2}} R_{\Psi}^{\prime}\left(R-R_{\Psi}\right)}\right\} \\
\left\langle B_{p}^{2}\right\rangle=\left(\frac{2 \Psi_{0} \rho}{a^{2} R_{\Psi}}\right)^{2}\left\{\frac{1+\varepsilon / d\left[1-\left(1-d^{2}\right)\right]^{\frac{1}{2}}}{\left(1-d^{2}\right)^{\frac{1}{2}}}\right\},
\end{gathered}
$$

where $d=2 \Psi_{0} \rho R_{\Psi}^{\prime} / a^{2}$ and $\varepsilon=a / R_{\Psi}$.

The poloidal magnetic field defined in Eq. (12) possesses the basic characteristic that, as the plasma shift specified by $R_{\Psi}^{\prime}$ increases in response to heating, there will be an increase of poloidal magnetic field at larger major radii. In order to establish the relationship between the shift $R_{\Psi}^{\prime}$ and the heating process, we require a relationship between the magnetic equilibrium specified by Eqs. (10) through (12) and plasma force balance. This can be obtained in a simple manner by using the method given by Shafranov. ${ }^{10}$ The Virial theorem, which involves an average over the particle and magnetic pressures contained within the entire plasma, is

$$
\int\left(p+\frac{B^{2}}{8 \pi}\right) \cdot d V=\int\left(p+\frac{B^{2}}{8 \pi}\right) \cdot \vec{r} \cdot d \vec{S}_{I}
$$


The integral form of the plasma force balance equation, applied to a wedge of the toroidal plasma between a toroidal angle $\Phi$ and $\Phi+d \Phi$, is

$$
\int\left(p+\frac{B_{p}^{2}}{8 \pi}-\frac{B_{\Phi}^{2}}{8 \pi}\right) d S_{\Phi}=\int\left(p+\frac{B^{2}}{8 \pi}\right) \hat{i}_{R} \cdot d \vec{S}_{2} .
$$

Using these equations and the magnetic flux function defined in Eq. (10) leads to the following equations:

$$
\begin{gathered}
\bar{p}+\frac{B_{\Phi}^{2}-B_{e}^{2}}{8 \pi}=\frac{B_{u}^{2}}{8 \pi\left(1-d^{2}\right)^{\frac{3}{2}}}, \\
\left\{\frac{-d}{t} \frac{1}{\left(1-d^{2}\right)^{\frac{3}{2}}}-\frac{1}{2\left(1-u^{2}\right)^{\frac{3}{2}}}+\frac{\left[1-\left(1-d^{2}\right)^{\frac{1}{2}}\right]}{u^{2} \cdot\left(1-a^{2}\right)^{\frac{1}{2}}}\right\} \\
=\bar{B}_{a}+\frac{b_{i}}{2},
\end{gathered}
$$

where $B_{a}=2 \Psi_{0} / a R_{\Psi_{0}}$ and $\bar{\beta}_{a}=8 \pi \bar{p} / B_{a}^{2}$.

In the low beta case when $\bar{B}_{a}$ is on the order of unity, Eq. (16) tells us that the shift parameter $d$ must be of order $\varepsilon$; consequentiy Eqs. (15) and (16) reduce to Shafranov's low beta equations. In the opposite limit, when $\bar{\beta}_{a}$ is assumed to be on the order of $e^{-1}$, d must approach unity.

Equation (16) can be viewed as defining the value of $d$ corresponding to the pressure existing in the plsama, and Eq. (15) can be viewed as giving the depth of the toroidal field well produced by the shifts or deviations from noncircularity in the plasma.

One can define the plasma poloidal beta, $\beta_{p}$, as

$$
\beta_{p}=\bar{\beta}_{a} \frac{B_{a}^{2}}{\left\langle B_{p}^{2}\right\rangle}
$$


Using the poloidal field defined in Eq. (12), the plasma poloidal beta becomes

$$
\beta_{p}=\bar{\beta}_{a} \frac{\left(1-d^{2}\right)^{\frac{1}{2}}}{\left\{1+\frac{\varepsilon}{d}\left[1-\left(1-d^{2}\right)^{\frac{1}{2}}\right]\right\}}
$$

and in the high beta limit

$$
\beta_{p} \cong \frac{2}{\beta^{3}} / \epsilon^{\frac{1}{3}}
$$

Figure 11 shows the dependence of $\beta$ and $\beta_{p}$ on $\bar{\beta}_{a}$. Figure 12 shows the development of the toroidal well as a function of $d$. As in the high beta limit of Eq. (16), we find that the plasma poloidal beta increases as the two-thirds power of the pressure increase measured by $\bar{B}_{a}$. The remaining plasma pressure is supported by the toroidal well, the depth of which can be obtained from Eq. (15).

One further characteristic of flux-conserving tokamaks can be obtained by noting that the total current flowing in a tokamak can be written as

$$
I(\Psi)=\frac{V^{\prime}\left\langle B_{p}^{2}\right\rangle}{8 \pi}=\frac{\Psi_{0}}{R_{\Psi}}\left(1+\frac{\epsilon d}{?}\right) \frac{\left\langle B_{p}^{2}\right\rangle}{R^{2}}
$$

Using the circular flux surface model to calculate the average in Eq. (20), and using the high beta limit of Eq. (16) to determine $d$, we find that the total current flowing in a flux-conserving tokamak must increase as the one-third power of the pressure:

$$
I\left(\Psi_{0}\right)=\left(\Psi_{0} / R_{\Psi_{0}}\right) \quad 1+\frac{\varepsilon d}{2} \frac{\left\langle B_{p}^{2}\right\rangle}{B_{a}^{2}} \propto \bar{\beta}_{a}^{\frac{1}{3}} .
$$




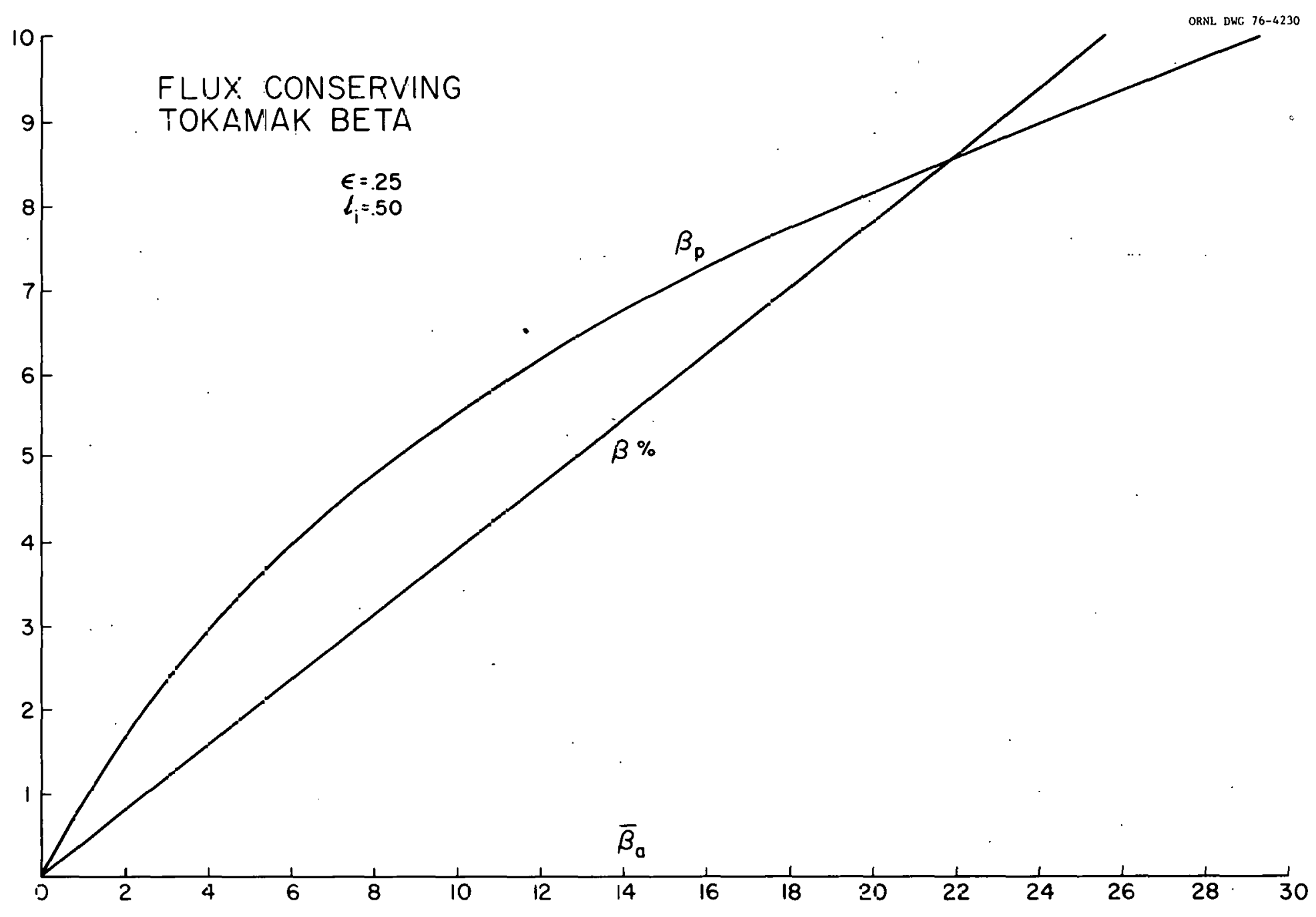

Fig. 11. Figure 11 shows the evolution of the poloidal and toroidal beta as the average plasma pressure ncrmalized to the initial poloidal field pressure is increased in a flux conserving manner. The total beta is seen to increase linearly whereas the poloidal beta has a tendency to saturate at high values of plasma pressure. 


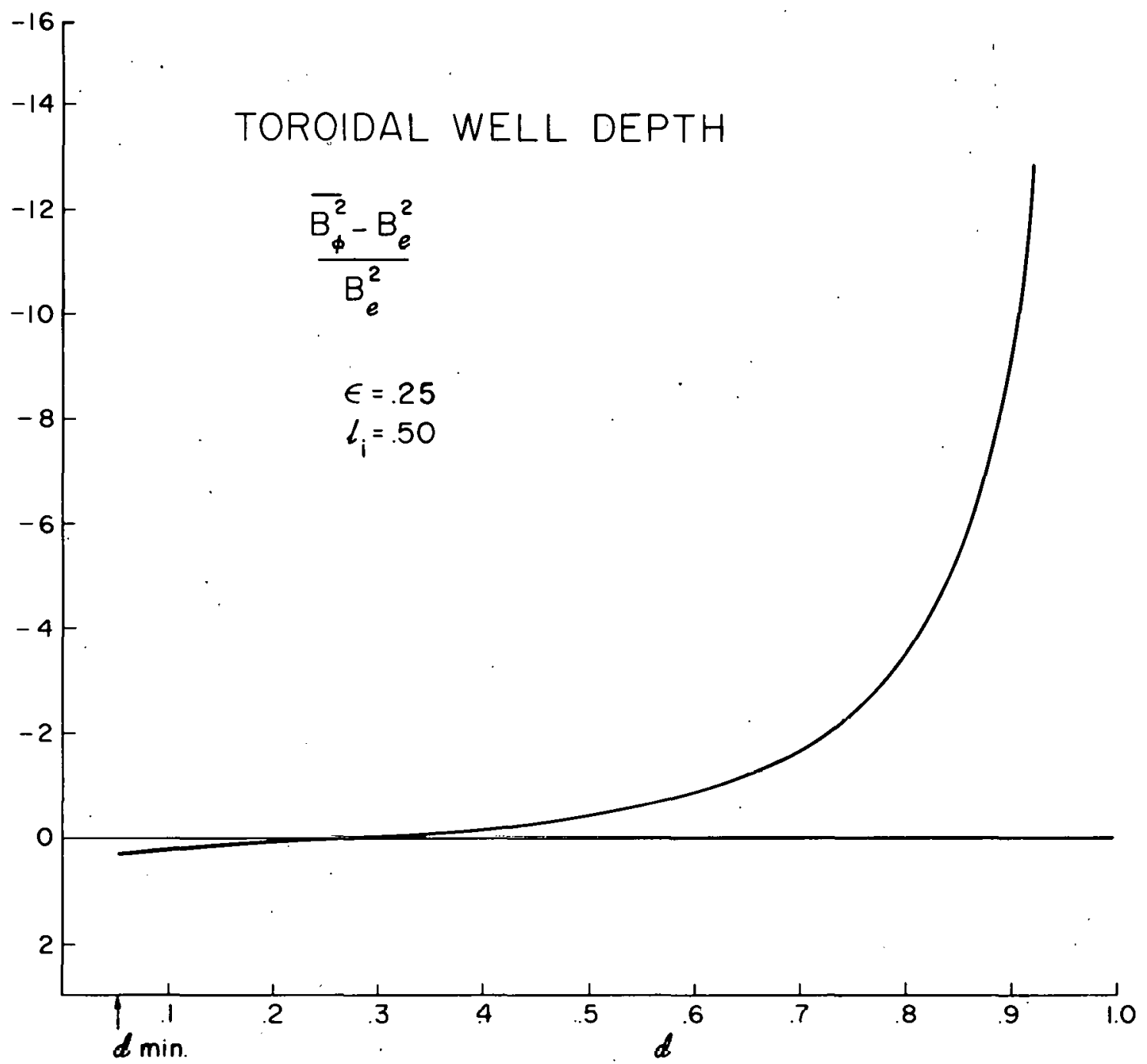

Fig. 12. Figure 12 shows the evolution of the toroidal well as a function of a parameter related to the displacement of the magnetic axis. The transition from a paramagnetic to a diamagnetic toroidal equilibrium is seen to occur as small values of $d$. The large increase in the toroidal well depth at large values of the parameter d results from the fact that most of the large plasma pressure is contained by the toroidal field for large d. 
An examination of Eq. (12b), which is valid throughout the bulk of the plasma, reveals another basic characteristic of flux-conserving tokamaks, the peaking of the toroidal current toward the surface of the plasma. From Eq. (20) we see that the current flowing within a given flux surface is directly related to the flux surface average of the square of the poloidal field as given in Eq. (12b). Since the parameter $d$ is an increasing function of flux, the increased current flowing at high beta as in Eq. (2l) can be seen to be distributed toward the surface of the plasma. It was a desire to avoid using "artificial" skinned current distributions which prevented Callen and Dory from realizing flux-conserving equilibria in their paper. Here we see that skinned currenl prufiles are not artificial but occur naturally as flux conservation requires the plasma current to increase.

This increase of current, will be driven by the plasma itself, but it must be balanced by an equal and opposite current flowing in the external winding which controls the spatial position of the plasma. The need to provide for this extra current is the only additional requirement for the design of a flux-conserving tokamak as opposed to a standard tokamak in which the plasma current windings are controlled so as to regulate the current to a constant value. Since the q profile is frozen in a fluxconserving tokamak, there is no need to regulate the total plasma current. Indeed, as seen from $\mathrm{Tq}$. (21), there is a definite need to program an increase in the current flowing in the plasma control windings as the plasma is heated. In addition, the asymmetry which is built into the poloidal field in Eq. (12) is reflected in a need to rearrange the distribution of plasma control winding current as the plasme pressure is increased.

Since the numerical results for the shape of high beta flux-conserving. equilibria show a natural D-shape, we have analyzed the distribution of currents which would be required to sustain such an equilibrium. Figure 13 shows a typical case. A set of coils located on the contour I at a distance $d$ from the surface of the plasma is used to provide the equilibrium as the beta poloidal of the plasma is increased by a heating technique. Figure 14 shows the distribution of currents on the surface $L$ during this heating process for two different values of the separation d. It is clear 


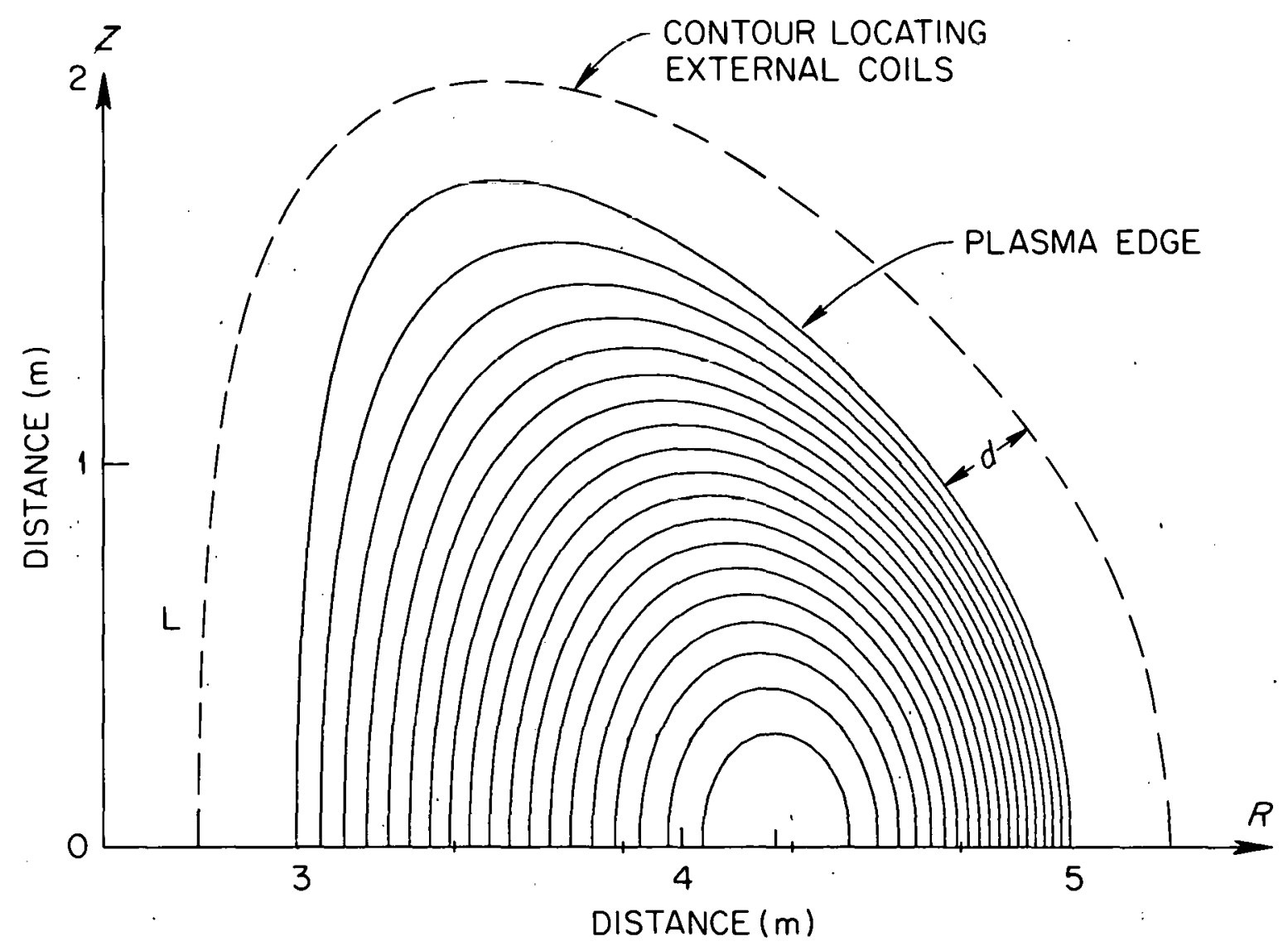

Fig. 13. Figure 13 shows a set of magnetic flux surfaces for a $D$ shaped plasma maintained in equilibrium by a set of conductors located a distance d from the plasma surface. The computations were done for a plasma with $\varepsilon=.25$, an elongation of 1.65 , and a beta poloidal of 2.4 . 
ORNL-DWG $76-4267$
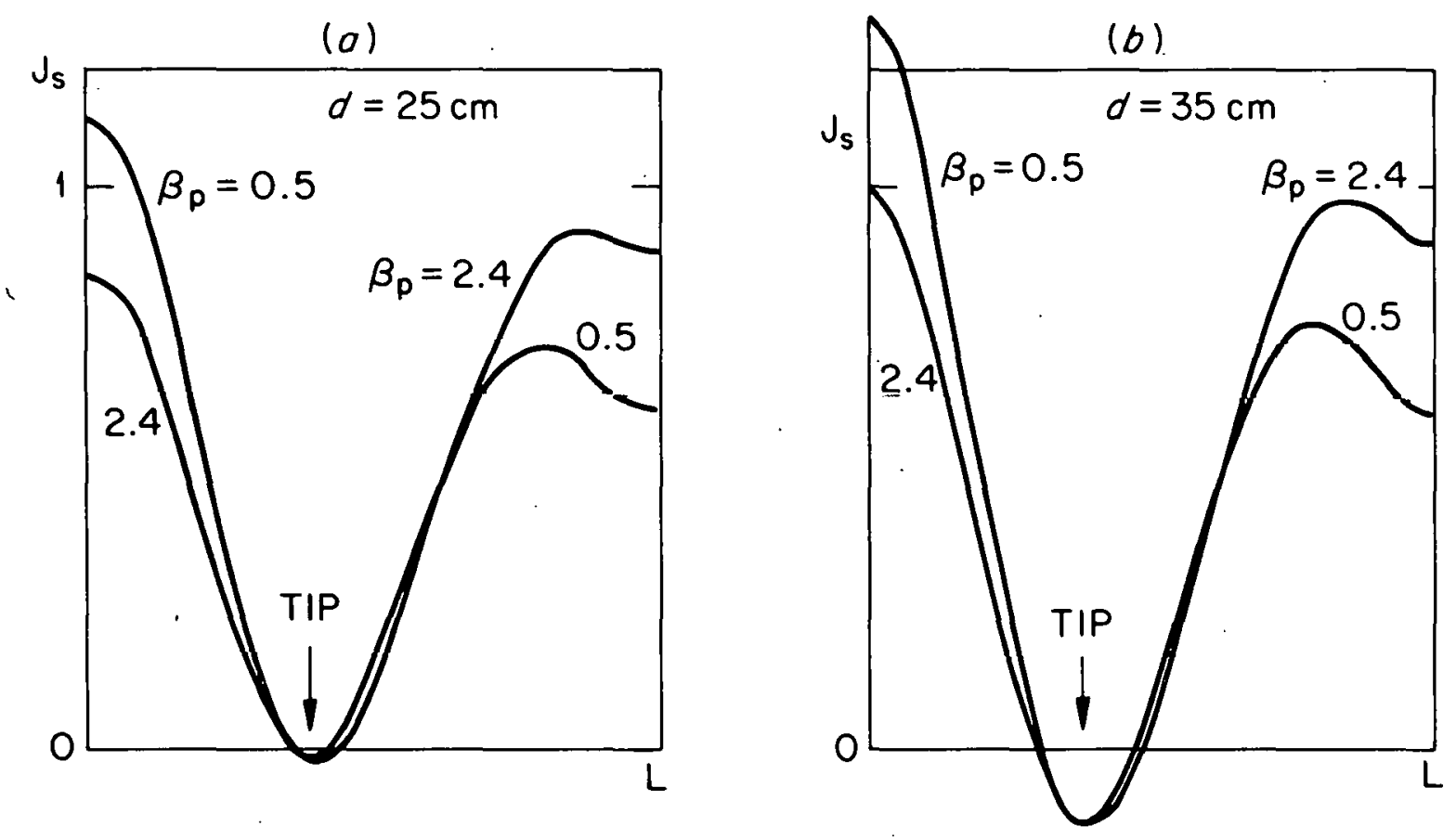

Fig. 14. Figure 14 shows the current distribution along the contour $\mathrm{L}$ of Figure 13 necessary to maintain the plasma in equilibrium as the poloidal beta is raised from .5 to a value of 2.4. For two values of the separation distance, the current distribution for the higher beta plasma shifts (as expected) from the interior of the contour to the exterior. As the equilibrium coils are shifted further from the plasma surface, negative currents must be generated in the region of the plasma tip. No drastic modification of the current distribution is required to maintain the high beta plasma in equilibrium. 
from the calculations that it is possible to sustain these equilibria with currents flowing in a shell at a reasonable distance from the plasma, thus allowing the inclusion of coil shielding and structure. It is also apparent that the changes in the distribution of the currents flowing on the contour $L$ need not be extreme as the plasma pressure is raised. In fact, some of the current changes shown in the figure could be produced by utilizing low-impedance constant voltage power supplies for the coils. This would allow the plasma itself to induce the necessary current changes.

\section{CONCLUSION}

Numerical and analytic studies have shown that plasmas subject to external heating will naturally seek high beta equilibria whose characteristics are determined by flux conservation. These equilibria can be characterized by broad pressure profiles and plasma currents peaked toward the plasma surface. They possess the same $q$ profiles as the low beta. equilibria from which the heating commences, and consequently have reasonable stability properties against local MHD modes. These equilibria are naturally noncircular and tend to approximate a D-shape with moderate elongation of roughly one and one-half. The technological requirements for sustaining such equilibria are not extreme. Their confinement characteristics are such that one can contemplate attaining ignition conditions in moderate-size plasmas. The one remaining factor which must be analyzed is the stability of these equilibria to MHD modes. In this regard, there is no reason to suspect difficulty at moderate beta. However, since these equilibria have the capability of attaining arbitrarily high beta as tar as the equilibrium of the plasma is concerned, it is important to investigate the limitations imposed on maximum attainable beta by MHD stability theory. 
THIS PAGE

WAS INTENTIONALLY

LEFT BLANK 
REFERENCES

1. M. Roberts and E. S. Bettis, Oak Ridge Tokamak Experimental Power Reactor Study Reference Design, ORNL/TM-5042, Oak Ridge (November 1975).

2. GAC Fusion Engineering Staff, Experimental Power Reactor Conceptual Design Study, GA-Al35.34, San Diego, California, Prepared for Electric Power Research Institute. (July 1975).

3. W. M Stacey et al., Tokamak Experimental Power Reactor Studies, ANL/CTR-75-2, Argonne, Illinois (June 1975).

4. G. L. Kulcinski and R. W. Conn, "The Conceptual Design of a Tokamak Fusion Power Reactor," UWMAK-1, Proc. First Topical Meeting on the Technology of Controlled Nuclear Fusion, CONF-740402 1, 38 (1974).

5. V. S. Mukhovatov and V. D. Shafranov, Nucl. Fusion 11, 605 (1971).

6. J. D. Callen and R. A. Dory, Phys. Fluids 15, 1522 (1972).

7. Y-K. M. Peng et al., Magnetohydrodynamic Stability of Axisymmetric Tokamak Equilibria, ORNL/TM-5267, Oak Ridge (To be Published).

8. R. A. Dory, Y-K. M. Peng, and F. B. Marcus, "Flux Conserving Equilibria for Tokamaks," Theory Department Memo \#76/29 (ORNL), March 22, 1976.

9. R. A. Dandl et al., The Elmo Bumpy Torus Experiment, ORNT./TM-3694, Oak Ridge (November 1971).

10. V. D. Shafranov, Reviews of Plasma Physics 2, 103 (1966).

11. Y-K. M. Peng, "Recent Results on the High-Beta 'l'okamak Equilibrium, Stability and Poloidal Field Design Pertaining to TNS," Theory Department Memo \#76/37 (ORNL), April 8, 1976. 


\section{THIS PAGE WAS INTENTIONALLY LEFT BLANK}


Internal Distribution

ORNL/TM-5429

1. I. A. Berry

2. J. D. Callen

3-12. J. F. Clarke

13. F. L. Culler

14. R. A. Dandl.

15. C. A. Flanagan

16. P. N. Haubenreich

17. G. G. Kelley

18. H. M. Long

19. O. B. Morgan

20. H. Postma
21. M. Roberts

22. M. W. Rosenthal

23. D. Steiner

24. L. D. Stewart

25-26. Central Research Library

27. Document Reference Section

28. ORNL Patent Office

29. Laboratory Records, RC

30-31. Laboratory Records

32. Thermonuclear Division Library

33. CTR Reports Office

\section{External Distribution}

34. Director, Division of Research and Technical Support, USERDA-ORO

35. D. J. Anthony, General Electric Company, Energy Systems and Technical Division, 1 River Road, Schenectady, NY . 12345

36. S. J. Buchsbaum, Executive Director, Research Communications Science Division, Bell Laboratory, Crawford Corner Road, Holmdel, NJ 07733

37. R. W. Bussard, 462 Santa Cecelia, Solana Beach, CA 92075

30. A. T. Christensen, Manager, Program Development, General Electric Company, 777 14th Street, N.W., Washington, DC 20005

39. R. W. Conn, Department of Nuclear Engineering, University of Wisconsin, Madison, WI 53706

40. E. C. Creutz, Assistant Director for Research, National Science Foundation, 1800 G. Street, N.W., Washington, DC 20550

41. S. O. Dean, Assistant Director for Confinement Systems, Division of Controlled Thermonuclear Research, USERDA, Ma1l Stop G-234, Washington, DC 20545

42: S. Fernbach, Lawrence Livermore Laboratory, University of California, P. 0. Box 808, Livermore, CA 94551.

43. T. K. Fowler, Associate Director, Lawrence Livermore Laboratory, University of California, P. O. Box 808, Livermore, CA 94551

44. H. P. Furth, Co-Head Experimental Division, Plasma Physics Laboratory, Princeton University, P. O. Box 451, Princeton, NJ 08540

45. F. C. Gilbert, Division of Military Application, USERDA, Washington, DC 20545

46. M. B. Gottlieb, Director, Plasma Physics Laboratory, Princeton Universit.y, P. 0. Box 451, Princeton, NJ 08540

47. W. C. Gough, Electric Power Research Institute, 3412 Hillview Avenue, P. O. Box 10412, Palo Alto, CA 94304

48. R. W. Gould, Department of Applied Physics, California Institute of Technology, Pasadena, CA 91109 
49. J. N. Grace, Technical Project Officer, Division of Controlled Thermonuclear Research, USERDA, Mail Stop G-234, Washington, DC 20545

50. H. Grad, Courant Institute, New York University, 251 Mercer Street, New York, NY 10012

51. G. K. Hess, Jr., Senior Scientific Advisor, Division of Controlled Thermonuclear Research, USERDA, Mail Stop G-234, Washington, DC 20545

52. R. L. Hirsch, Director, Division of Controlled Thermonuclear Research, USERDA, Mail Stop G-234, Washington, DC 20545

53. E. S. Keen, Boeing Company, 102 Tưlsa Road, Oak Ridge, TN 37830

54. E. E. Kintner, Deputy Director, Division of Controlled Thermonuclear. Research, USERDA, Mail Stop G-234, Washington, DC 20545

55. B. Miller, Assistant Director for Research, Divisinn of Controlled Thermonuclear Research, USERDA, Mail Stop G-234, Washington, DC 20545

56. T. Ohkawa, General Atomic Company, P. O. Box 81608, San Diego, CA 92212

57. P. J. Reardon, Head of Tokamak Fusion Test Reactor, Plasma Physics Laboratory, Princeton University, P. O. Box 451, Princeton, NJ 08540

58. F. L. Ribe, Division Leader, CTR Division, Los Alamos Scientific Laboratory, P. O. Box 1663, Los Alamos, INM 87544

59. D. J. Rose, Department of Nuclear Engineering, Massachusetts Institute of Technology, Cambridge, MA 02139

60. Z. Shapiro, Executive Assistant to the General Manager, Breeder Reactor Division, Westinghouse Electric Corporation, P. O. Box 355, Pittsburgh, FA 15230

61. A. Trivelpiece, Department of Physics \& Astronomy, Universitiy of Maryland, College Park, MD 20742

62. H. H. Woodson, Chairman, Department of Electrical Fingineering, The University of Texas at Austin, Austin, TX 78712

63-89. Technical Information Center, USERDA-ORO 